\title{
Wolfgang Ruppert (dir.), Künstler im \\ Nationalsozialismus. Die "deutsche Kunst », die Politik und die Berliner Kunsthochschule
}

Hélène Ivanoff

\section{CpenEdition}

Édition électronique

URL : http://journals.openedition.org/ifha/8769

DOI : $10.4000 /$ ifha 8769

ISSN : 2198-8943

\section{Éditeur}

IFRA - Institut franco-allemand (sciences historiques et sociales)

Référence électronique

Hélène Ivanoff, «Wolfgang Ruppert (dir.), Künstler im Nationalsozialismus. Die «deutsche Kunst », die Politik und die Berliner Kunsthochschule », Revue de l'IFHA [En ligne], Date de recension, mis en ligne le 02 novembre 2017, consulté le 24 septembre 2020. URL : http://journals.openedition.org/ifha/8769 DOI : https://doi.org/10.4000/ifha.8769

Ce document a été généré automatiquement le 24 septembre 2020.

(CIFHA 
Wolfgang Ruppert (dir.), Künstler im Nationalsozialismus. Die " deutsche Kunst ", die Politik und die Berliner Kunsthochschule

Hélène Ivanoff

\section{RÉFÉRENCE}

Wolfgang Ruppert (dir.), Künstler im Nationalsozialismus. Die « deutsche Kunst », die Politik und die Berliner Kunsthochschule, Köln: Böhlau, 2015, 372 p., 44,90€ 
Le livre édité par Wolfgang Ruppert, professeur d'histoire politique et culturelle à l'Université des Arts de Berlin (Universität der Künste, UDK), rassemble 16 contributions richement illustrées de 120 reproductions (dont plus de la moitié en couleurs) qui analysent le passé de cette institution artistique sous la période du nazisme.

Nées en 1924 de la fusion de l'École supérieure des Beaux-Arts (Hochschule für die bildenden Künste) et de l'Institut éducatif du Musée des Arts décoratifs (Unterrichtsanhalt des Kunstgewerbemusems), les écoles publiques de Berlin pour l'art libre et appliqué (Berliner Vereinigten Staatsschulen für freie und angewandte Kunst, VS) étaient un lieu

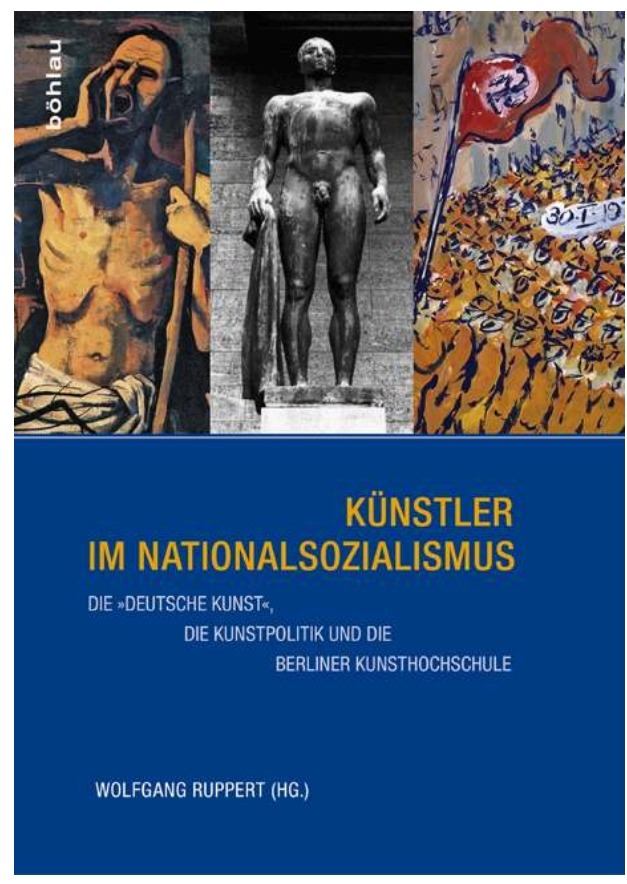
d'enseignement fondé sur la pratique et la diversité artistique, dépassant les frontières entre art et artisanat et incarnant l'esprit de la réforme culturelle prônée sous la République de Weimar, qui avait également permis la création du Bauhaus. Tandis que le Bauhaus fermait ses portes à Dessau en 1932 et était dissous à Berlin en 1933, les VS furent «embrigadées ", « nettoyées » de leurs conceptions artistiques et culturelles hybrides en étant réunies au sein de l'École supérieure d'État des Beaux-Arts (die Staatliche Hochschule für bildende Künste), qui devient, après la guerre et suite à différentes fusions, l'Université des Arts de Berlin. L'ouvrage est ainsi issu des réflexions d'un colloque, tenu à l'automne 2013 au cours duquel l'UDK a entrepris l'examen de sa propre histoire, dont les racines remontent au XVII ${ }^{e}$ siècle. Croisant les parcours biographiques avec les évolutions de la politique culturelle du régime nazi, le livre illustre la mise au pas d'une institution culturelle, les compromissions, les persécutions et les résistances de ses étudiants et de ses professeurs.

Introduisant l'analyse par des études biographiques des membres de l'école (Karl Hofer, Oskar Schlemmer, Kurt Schumacher, Émile Nolde, Käthe Kollwitz, Arno Breker et Josef Thorak), W. Ruppert dresse un panorama de ces années de terreur en distinguant plusieurs phases: la prise en main de l'institution par les nazis concomitante de la définition de ce qu'est l'art allemand, la valorisation de l'«art allemand» et la stigmatisation de l'« art dégénéré » à partir de la double exposition de Munich en 1937, la radicalisation de cette politique culturelle pendant la Seconde Guerre mondiale. La première partie du livre, "L'art allemand, l'art dégénéré et la politique artistique ", porte sur les cadres culturels et politiques nationaux imposés par le régime: de la création de la Chambre d'État pour les Beaux-Arts (Nina Kubowitsch), aux grandes expositions d'« art allemand " des années 1937-1944 (Christian Fuhrmeister) et à la surveillance politique de la Seconde Guerre mondiale (Otto Karl Werckmeister). La deuxième partie, «Institutions - des conceptions différentes de l'art », met en exergue l'histoire parallèle de deux institutions artistiques: les VS de Berlin affectées par la Révolution nationale (Stefanie Johnen) et l'Académie des Arts de Düsseldorf où 
enseignèrent Paul Klee, Heinrich Campendonk et Oskar Moll (James A. van Dyke). La troisième partie est axée sur " les artistes entre indépendance, adaptation et adhésion à la création artistique dite allemande ", et s'intéresse notamment à Karl Hofer, opposant au national-socialisme (Andreas Hünecke), et à Oskar Schlemmer dont la position a été plus ambivalente en 1933/1934 (Magdalena Droste). Elle évoque aussi les débats à partir des années 1933/1934 concernant la conformité de l'expressionisme avec le style "allemand» (Eckart Gillen), se caractérisant par la monumentalité dans la sculpture (Josephine Gabler). La dernière partie, « Être artiste contre la majorité dans la culture nazie ", interroge les conditions de création de différents artistes à l'instar de Käthe Kollwitz, exclue de l'école en raison de ces engagements politiques en 1933 (Maria Derenda), d'Émile Nolde faisant allégeance au régime tout en étant finalement frappé d'interdiction de peindre en 1941 (Bernhard Fulda), de Felix Nussbaum, forcé de s'exiler en raison de ses origines juives et déporté à Auschwitz en 1944 (Anne Sibylle Schwetter), du sculpteur Fritz Cremer, militant communiste poursuivant pourtant sa carrière sous le nazisme (Gerd Brüne), des artistes de la Klosterstrasse exerçant dans leur atelier commun (Angela Lammert), et enfin de l'étudiante juive Charlotte Salomon, auteur de "Vie ou théâtre ? ", déportée à Auschwitz en 1943 (Christine Fischer-Defoy).

Le livre apporte en somme un éclairage essentiel sur la création artistique et la politique culturelle des années 1933-1945 à travers l'étude d'une institution artistique majeure de l'époque.

\section{INDEX}

Index chronologique : Époque contemporaine

Thèmes : Histoire de l'art

\section{AUTEURS}

HÉLĖNE IVANOFF

EHESS (CNRS-UMR 8131) 